\title{
Gain in Knowledge of Farmers Regarding Integrated Pest Management Technology through Need-Based Community Radio Programme
}

\author{
Pragya Goswamy* and S. K. Kashyap \\ Department of Agricultural Communication, G B Pant University of Agriculture and \\ Technology, Pantnagar 263145, India \\ *Corresponding author
}

\section{A B S T R A C T}

\section{Keywords}

IPM, knowledge,

Community radio programme,

Participation, Needassessment

\section{Article Info}

Accepted:

17 June 2020

Available Online:

10 July 2020
Integrated Pest Management (IPM) is a sustainable and holistic approach of pest control, causing reduction in pesticide usage, decreased cost of production and low risk on human health and environment but still farmers have shown limited interest in practicing this method. The present study assessed the prevailing level of knowledge about integrated pest management concept and practices among the farmers of Nainital District of Uttarakhand and planned a need-based media intervention of community radio programme with the participation of local people. Need-based and participatory community radio programme was found significantly effective in enhancing the knowledge of farmers regarding IPM concept and practices. It was reported that at 0.01 level of significance post-knowledge test score of respondents was significantly higher than pre-knowledge test score, following which it was concluded that community radio programme is significantly effective in terms of gain in knowledge. Thus, the study reveals that mediation of 'ICTenabled medium as Community Radio Service' and 'participatory methodology' should be used by extension agencies in large scale throughout to bridge the existing gap. It also supported that mediation of 'participation' significantly promotes and enhances adoption of agricultural technologies.

\section{Introduction}

Agriculture plays a pivotal role in Indian economy. The green revolution of $1960 \mathrm{~s}$ transformed India from a state of hunger and famine to a self-sufficient nation in food grain production. Introduction of high yielding varieties and use of fertilizers and pesticides though increased the production on one hand but on the other hand, the injudicious and indiscriminate use of pesticides created many problems over the years. Pesticides have polluted almost all parts of our environment. Pesticide residues are found in soil, air and water bodies across the country. It has also led to downfall in the number of beneficial insects and has caused pest resurgence and resistance against pesticides. Farming community has faced with major challenges due to increased cost of production and emergence of new pests and diseases one after another. This furthered the development of a 
holistic approach aimed at limiting the pest population below the economic injury level. This holistic approach was named as Integrated Pest Management (IPM) with focus on judicious use of pesticides and effective management of pest population.

According to FAO definition, Integrated Pest Management (IPM) means the careful consideration of all available pest control techniques and subsequent integration of appropriate measures that discourage the development of pest populations and keep pesticides and other interventions to levels that are economically justified and reduce or minimize risks to human health and the environment.

Advantages of IPM methods in crop production includes; lower production cost, decreased environment pollution, improved soil and water quality, conservation of natural enemy species and biodiversity and reduced farmer risks from pesticide poisoning (Krishna et al., 2003). Although IPM has been accepted in principle, as the most attractive option for protection of agricultural crops from the destruction of pests, its implementation at farm level in India had been limited (Puri 1998). Kyamanywa (2001) revealed that rural farmers are still not informed and aware regarding the implementation methods of IPM. IPM is a knowledge based and knowledge intensive technology and the knowledge-intensive nature of IPM means that most important prerequisite for the adoption of IPM technology is improved knowledge of farmers (Goyal 2006; Allahyari et al., 2017). To harness the potential of IPM technology it is of paramount importance that a planned strategy should be adopted to extend this technology to rural farmers. Many researchers believe that participatory methods can be more effective in IPM technology adoption by farmers (Asiabaka 2002). It was also reported that IPM programs could only succeed when aligned with the knowledge, skills and motivation of farmers and seek the participation of local groups (Razzagh et al., 2013).

\section{Effective communication of agricultural technology: IPM}

With time, radio became instrumental for social change due to its obvious virtues of simplicity, cost-effectiveness, transportability and location specificity and has emerged as a key tool for participatory communication. More specifically, after the declaration of Supreme Court in 1995 that 'airwaves are public property' a yet another form of radio emerged in our nation called community radio. The concept of community radio made it the radio, which airs the voice of a localized community. The community is identified as a group, not simply a mass of people that the broadcasting signal happens to cover. A group of people who form relationships over time by interacting regularly around shared experiences, which are of interest to all of them for varying individual reasons is a community. 'Participation' is often highlighted as a key characteristic, distinguishing community radio from most other kinds of media (Mtimde et al., 1998). Community radio promotes local discussion within the community to assess their environment, the causes for their problems and explores possible actions can be took to address the situations.

There are multiple examples in which communication could not attain expected changes due to people's initial lack of involvement or limited understanding of issues by various stakeholders. Therefore, looking into the participatory and need based approach of community radio it was chosen for the present study, to test whether it can be utilized as an innovative media intervention 
for disseminating IPM technology and bring significant change in farmers' knowledge about IPM concept and practices. The present study was undertaken with objectives to assess the level of knowledge about IPM concept and practices among farmers of Nainital District of Uttarakhand, to design need-based community radio programme, test its effectiveness in terms of gain in knowledge of the farmers.

\section{Materials and Methods}

\section{Study area and sample selection}

For this study Pantnagar Janvani, the community radio service of the first Agricultural University of the Nation, GB Pant University of Agriculture and Technology, Pantnagar was purposively selected. Pantnagar Janvani acts as a medium of extension, of latest technologies and scientific methods to farmers and seeks to bridge the information gaps with the latest and relevant information shared by experts of various different subjects like agriculture, veterinary, animal sciences, etc. The study was conducted in the four randomly selected villages of the Haldwani block of Nainital district of Uttarakhand, which catches the efficient signals of community radio, Pantnagar Janvani. Total 120 respondents were selected through Probability proportionate to size (PPS) sampling method. Keeping the study objectives in mind, the study followed an action research design.

Effectiveness of community radio program in terms of gain in knowledge assessed through pre and post knowledge test

$\mathrm{H}_{0}$ (Null hypothesis): There is no difference between the mean pre-test score $\left(\mu_{1}\right)$ of respondents and mean post-test score $\left(\mu_{2}\right)$ of respondents. $\left(\mathrm{H}_{0:} \mu_{1}=\mu_{2}\right)$
$\mathrm{H}_{1}$ (Alternate hypothesis): Mean post-test score of respondents is significantly greater than mean pre-test score of respondents. $\left(\mathrm{H}_{1}\right.$ : $\left.\mu_{1}<\mu_{2}\right)$

\section{Data collection tools and technique}

Focused group discussion was conducted and an information need assessment questionnaire was administered to assess the information need of respondents regarding Integrated Pest Management. A Knowledge test was constructed to assess the level of knowledge of respondents on various aspects of IPM. Questions were related to three broad categories i.e., IPM: a concept, Non-chemical methods of integrated pest management and chemical method of integrated pest management. Total number of 37 questions, which covered all possible aspects of the content related to IPM were selected for construction of Knowledge test. Responses were quantified by giving a score of 'one' for appropriate answer and 'zero' for wrong answer. Knowledge test was validated by experts of Agronomy, Entomology and Plant Pathology. Reliability of the knowledge test was assessed through split half method.

\section{Data analyses}

Statistical technique such as frequency, percentage, mean, weighted mean score, standard deviation, t-test, correlation coefficient and paired t-test were used to analyze the data for meaningful interpretation.

\section{Results and Discussion}

\section{Designing of Community radio programme on IPM}

For this study, the researcher followed the steps with slight modifications as directed in the Participatory Community Radio Module developed by Sharma and Kashyap (2016). 
Steps for participatory programme designing followed in the study were as follows:

\begin{tabular}{|l|l|}
\hline Steps & Activities \\
\hline Step 1 & Rapport Building \\
\hline Step 2 & General Information and \\
\hline Step 3 & Prioritization of needs \\
\hline Step 4 & Designing participatory \\
\hline Step 5 & Broadcasting Community \\
\hline
\end{tabular}

\section{Step 1: Rapport Building}

The first phase was rapport building in which informal talk, door to door visit and transect walk were organized. Researcher invested one to two days in each village for the process of rapport building.

\section{Step 2: General information and Need Assessment}

General information related to socioeconomic, communication and psychological characteristics of respondents was sought through semi-structured interview schedule. The findings of the study revealed that majority of respondents $(64.17 \%)$ were of middle age group (27-52 years). None of the respondent was illiterate and maximum (36.67 \%) were educated up to high school level. It was found that almost all the respondents $(95 \%)$ were having marginal landholding ( $<1$ hactare) yet majority of them $(62.5 \%)$ had medium annual income (Rs. 45, 720 - Rs. 74, 815) might be because most of them $(62.15 \%)$ were engaged in agriculture $\&$ other subsidiary occupation. Majority of respondents $(62.5 \%$ and $79.17 \%)$ had medium achievement motivation and scientific orientation respectively. It was also found that majority of respondents $(80 \%)$ had medium mass-media exposure and 73.33 per cent had high information seeking behaviour. Among various information sources, personal localite sources were mostly preferred by most of the respondents and more than half of the respondents had no membership in any social organization.

Revelation of their needs by target audience and designing need-based programme is the first and major step to seek participation of target audience into the designing process. Therefore information need of respondents regarding various aspects of IPM was assessed using focused group discussion and structured interview schedule with three point continuum (score of 1, 2 and 3 was assigned) i.e., not aware (1 score), partially aware (2 score) and fully aware (3 score). Through consultation with experts three main heads viz., Concept of IPM, Non-chemical methods of pest management and Chemical method of pest-control were decided, on which the level of awareness of respondents was sought. These main heads were divided into certain sub-heads. After analyzing the responses, weighted mean score for each aspect was calculated.

\section{Step 3: Need Prioritization}

On the basis of weighted mean score (wms) assigned to each sub-issue, three categories were made viz., low awareness (wms between 1 to 1.66), medium awareness (wms 1.66 to 2.32) and high awareness (wms > 2.32).

\section{Concept of IPM}

As evident in Table 1, three issues with low awareness among respondents were prioritized and selected for designing first programme. Those three issues were, awareness regarding Pest Monitoring (weighted mean score 1.5), awareness regarding insect \& disease transmission through irrigation water (weighted mean score 
1.25) and Economic Threshold Level of pest (weighted mean score 1.00).

\section{Non-Chemical method of pest control}

As visible in Table 2, 12 issues with low awareness among respondents were prioritized and selected for designing second programme. Those twelve issues were, awareness regarding environment friendly method of residue management (weighted mean score 1.00), method to prevent the insecticidal resistance developed in insects (weighted mean score 1.50), pest management through intercropping (weighted mean score 1.50), awareness regarding light trap (weighted mean score 1.33), neem seed kernel extract (weighted mean score 1.25), soil-solarisation (weighted mean score 1.17), yellow sticky trap (weighted mean score 1.17), trap crop (weighted mean score 1.00), trichoderma (weighted mean score 1.00), pseudomonas (weighted mean score 1.00), pheromone trap (weighted mean score 1.00) and trichocard (weighted mean score 1.00).

\section{Chemical method of pest control}

As observed in Table 3, three issues with low awareness among respondents were prioritized and selected for designing third programme. Those three issues were, awareness regarding waiting period of pesticides (weighted mean score 1.42), toxicity labels of pesticides (weighted mean score 1.00) and appropriate timing for spraying pesticides (weighted mean score 1.00).

Thus, based on need assessment and prioritization, following aspects were selected for programme designing:

\section{Concept of IPM}

Pest monitoring, Mode of insect and disease transmission through irrigation water

Economic Threshold Level

\section{Non-Chemical methods of pest control}

Cultural method of pest management

Soil Solarisation

Pest Management through intercropping

Trap Crop

Biological method of pest management

Use of Trichoderma

Use of Pseudomonas

Mechanical method of pest management

Use of trichocard

Light trap

Yellow sticky trap

Pheromone trap

Environment friendly method of residue management

Method to prevent insecticidal resistance developed in insects

Neem Seed Kernel Extract

Non-Chemical method of stored grains pest management

\section{Chemical method of pest control}

Waiting period of pesticides

Toxicity label of pesticides

Appropriate timing of spraying pesticides

\section{Step 4: Designing participatory radio programme}

For designing the community radio programme, primarily the format and language of presentation was selected through focused group discussion with respondents. Preference of respondents was sought regarding the duration of programme and time of broadcast. Thereafter, script was designed and recorded with the participation of few community members who were actively involved into programme production process of community radio.

Total three programmes were designed and 
broadcasted. All the three programmes were in Hindi language and Kumaoni dialect based on the preference of the respondents. Information related to topic, format, duration and schedule of the broadcast of community radio programmes has been presented in Table 4.

\section{Step 5. Broadcasting of community radio programme}

Designed need-based community radio programme were broadcasted according to pre-decided schedule.

\section{Effectiveness of community radio programme in terms of gain in knowledge}

Effectiveness of community radio programme was measured using Knowledge test. Primarily, a knowledge test was given to respondents before the intervention of community radio programme that was called pre-test. Pre-test was then followed by a posttest. Paired ' $t$ ' test was calculated to test the significant difference in pre and post knowledge level of respondents. Data presented in Table 5 depicts the relevant values for driving conclusion from paired ' $t$ ' test.

It is evident from the above table that value of ' $t$ ' cal is higher than value of ' $t$ ' tab at $1 \%$ level of significance. Thus, null hypothesis that respondents have same knowledge in pre and post knowledge test was rejected and alternate hypothesis that mean knowledge score of respondents was significantly higher in post-test than pre-test was accepted. Hence, it can be concluded that the intervention of community radio programme led to significant gain in knowledge of respondents. Yelvattimath et al., (2014) and Sultana (2015) who also reported that there was a positive effect of radio broadcast on gain in knowledge of respondents, supported the findings of the study.

Initially farmers had low knowledge regarding IPM concept and practices as indicated by low score in pre-test $(\overline{X 1}=9.29)$. Significant increase in knowledge can be observed after the intervention of community radio programme, as the mean knowledge-test score increased from 9.29 to 24.1. The gain in knowledge was 14.81 . Thus, community radio programme was found to be effective in terms of gain in knowledge of respondents. Hence, the intervention of community radio programme can be used as an effective medium to enhance the level of knowledge of its listeners. It can also be concluded that when programme is designed based on needs of the respondents, positive results can be obtained in not only in bridging the information and knowledge gap but in all other possible aspects also.

Table.1 Distribution of issues based on the level of awareness of respondents related to concept of IPM

\begin{tabular}{|l|l|r|}
\hline S.No. & Category & $\begin{array}{c}\text { No. of } \\
\text { issues }\end{array}$ \\
\hline 1. & Low Awareness (wms 1 -1.66) & 3 \\
\hline 2. & Medium Awareness (wms 1.66-2.32) & 1 \\
\hline 3. & High Awareness (wms > 2.32) & 3 \\
\hline
\end{tabular}


Table.2 Distribution of issues based on the level of awareness of respondents related to nonchemical method of pest management

\begin{tabular}{|l|l|c|}
\hline S.No. & Category & No. of issues \\
\hline $\mathbf{1}$ & Low Awareness (wms 1 -1.66) & 12 \\
\hline $\mathbf{2}$ & Medium Awareness (wms 1.66-2.32) & 2 \\
\hline $\mathbf{3}$ & High Awareness (wms > 2.32) & 6 \\
\hline
\end{tabular}

Table.3 Distribution of issues based on the level of awareness of respondents related to chemical method of pest control

\begin{tabular}{|l|l|c|}
\hline S.No. & Category & No. of issues \\
\hline $\mathbf{1}$ & Low Awareness (wms 1 -1.66) & 3 \\
\hline $\mathbf{2}$ & Medium Awareness (wms 1.66-2.32) & 1 \\
\hline $\mathbf{3}$ & High Awareness (wms > 2.32) & 0 \\
\hline
\end{tabular}

Table.4 Designing of community radio programme on IPM

\begin{tabular}{|l|l|l|l|l|l|}
\hline $\begin{array}{l}\text { S. } \\
\text { No. }\end{array}$ & Topic & Format & $\begin{array}{l}\text { Date of } \\
\text { Broadcast }\end{array}$ & $\begin{array}{l}\text { Time of } \\
\text { Broadcast }\end{array}$ & $\begin{array}{l}\text { Duration of } \\
\text { the } \\
\text { Programme }\end{array}$ \\
\hline 1. & Concept of IPM & Magazine & 14 April & $5: 00 \mathrm{pm}$ & $10 \mathrm{~min}$. \\
\hline 2. & $\begin{array}{l}\text { Non-Chemical } \\
\text { methods of Pest } \\
\text { management }\end{array}$ & Drama & 15 April & $9: 00 \mathrm{am}$ & $25 \mathrm{~min}$. \\
\hline 3. & $\begin{array}{l}\text { Chemical methods } \\
\text { of pest control }\end{array}$ & Drama & 16 April & $5: 00 \mathrm{pm}$ & $15 \mathrm{~min}$. \\
\hline
\end{tabular}

Table.5 Paired ' $t$ ' test for relative effectiveness of community radio programme $(n=120)$

\begin{tabular}{|c|c|c|c|c|c|}
\hline $\begin{array}{l}\text { Mean of } \\
\text { pre-test } \\
\frac{X 1}{}\end{array}$ & $\begin{array}{l}\text { Mean of } \\
\text { post-test score } \\
X 2\end{array}$ & $\begin{array}{l}\text { Mean of } \\
\text { difference } \\
\bar{d}\end{array}$ & $\begin{array}{l}\text { Standard } \\
\text { deviation } \\
\text { difference } \\
S_{d}\end{array}$ & 't' cal & 't' tab \\
\hline 9.29 & 24.1 & 14.81 & 3.77 & $43.02^{* *}$ & -2.36 \\
\hline
\end{tabular}

** Indicate that value is significant at $1 \%$ level of significance

' $\mathrm{t}$ ' tab (left sided) $=-\mathrm{t}_{(\mathrm{n}-1, \alpha)}=-2.36$

This study provides conclusive evidence that there was significant gap in farmers' knowledge and awareness level regarding IPM technology and concepts before the intervention of community radio programme. The study also indicate that a planned and strategized media intervention, as need based community radio programme could significantly enhance the knowledge level of the farmers as in case of the present study. It was evident from the study that for effective dissemination of agricultural technologies like 
IPM, need assessment and participation of respondents is of paramount importance. The study has laid emphasis on the importance of need assessment of the respondents before designing any radio programme because if the programme is not need-based, neither respondents will be willing to give their time for it nor they would be willing to participate in the designing process. However, need assessment is in itself the foremost step of participatory process but equally important is to seek the participation of respondents in programme designing and production process like decision of format, language, duration and recording of programme by respondents. Need assessment and participatory programme designing together make the programme more impactful. In the present study, due to these two aspects viz., need assessment and participatory programme designing, significant gain in knowledge of the farmers was observed regarding IPM concept and practices. Similarly, participatory community radio programme can play a crucial role in dissemination of need-based agricultural information and transfer of technology. The findings were supported by the study of Yelvattimath et al., (2014) who reported that radio brings significant change in the knowledge level of the audience by providing useful and required knowledge to them.

For agricultural development, it is important that dissemination of agricultural information or technologies through planned media intervention like community radio programme must be need based and according to audience profile. Thus, being efficient to seek participation of audience and bridging the information gap, community radio can be a potential tool of agricultural extension.

\section{Acknowledgement}

Support provided by the team of community radio station, Pantnagar Janvani throughout the period of study is deeply acknowledged. Authors are also thankful to all the experts who validated the knowledge test to formulate a sound data collection tool.

\section{References}

Allahyari, M. S., Damalas, C. A. and Ebadattalab, M. 2017. Farmers' Technical Knowledge about Integrated Pest Management (IPM) in Olive Production. Agriculture 7: 1-9 (Retrieved from www.mdpi.com/journal/agriculture)

Asiabaka, C. 2002. Promoting Sustainable Extension Approach: Farmer Field School (FFS) and its Role in Sustainable Agriculture Development in Africa. International Journal of Agriculture \& Rural Development 3 (1) : 46-53.

Goyal, M.C. 2006. Adoption of Integrated Pest Management in Chickpea Production in Kota District of Rajasthan; Rajasthan, India. PhD Thesis, Maharana Pratap University of Agriculture and Technology, Udaipur, India. (Retrieved from http://krishikosh.egranth.ac.in/handle/1/ 5810010084)

Krishna, V. V., Byju, N. G. and Tamizheniyan, S. 2003. Integrated Pest Management in Indian Agriculture: A Developing Economic Perspective. Radcliffe's IPM World Textbook ed. E B Radcliffe, W D Hutchison and E Cancelado (St Paul, MN: University of Minnesota) (Retrieved from https://ipmworld.umn.edu/)

Kyamanywa, S. 2001. Current Status of Integrated Pest Management in Uganda. (Retrieved from http://www.ag.vt.edu/ail/proceedings/us aid.htm)

Mtimde, L. 1998. What is Community Radio? Panos. Southern Africa: AMARC Africa. 
Puri, S. N. 1998. Present Status of Integrated Pest Management in India. Paper presented at Seminar on IPM, Asian Productivity Organization at Thailand Productivity Institute, Bangkok.

Razzagh Borkhani, R., Rezvanfar, A., Fami, H. S. and Pouratashi, M. 2013. Social Factors Influencing Adoption of Integrated Pest Management (IPM) Technologies by Paddy Farmers. International Journal of Agricultural Management \& Development, 3: 211218.

Rogers, E. M. 2003. Diffusion of Innovations, 5th ed.; Free Press: New York, NY, USA.
Sharma, A. and Kashyap, S. K. 2016. Community radio: a community media module for empowerment of rural women. Media Asia, 42(3-4): 180-191.

Sultana, T. N. 2014. An Evaluation Study on Relevance of Radio for Promoting and Popularizing Organic Farming in Karnataka. (Retrieved from http://hdl.handle.net/10603/55942)

Yelvattimath, G. G., Nithyashree, D. A. and Devendrappa, S. 2014. Knowledge Gain of the Rural Women through Environment and Health Programmes. Karnataka Journal of Agricultural. Sciences, 27 (1): 67-70.

\section{How to cite this article:}

Pragya Goswamy and Kashyap, S. K. 2020. Gain in Knowledge of Farmers Regarding Integrated Pest Management Technology through Need-Based Community Radio Programme. Int.J.Curr.Microbiol.App.Sci. 9(07): 2048-2056. doi: https://doi.org/10.20546/ijcmas.2020.907.236 